\title{
CLINICAL MANAGEMENT OF IMMUNO- SUPPRESSION IN SPORTSMEN-WOMEN: RECOMMENDATIONS FOR SPORTS MEDICINE PHYSICIANS AND PHYSIOTHERAPISTS
}

\author{
ANTHONY C. HACKNEY ${ }^{1,2}$ \\ ${ }^{1}$ Applied Physiology Laboratory, Department of Exercise \& Sport Science \\ ${ }^{2}$ Department of Nutrition - Schools of Public Health-Medicine, \\ University of North Carolina, Chapel Hill, North Carolina, USA
}

\begin{abstract}
In sportsmen and sportswomen the Overtraining Syndrome (OTS) can be a physically debilitating medical condition that results in these men and women being totally compromised in their capacity to perform and compete athletically. Many physiological systems are affected by the process of overtraining and the OTS; but one system in particular, the immune, is highly susceptible to degradation resulting in a reduction in overall health and performance. The aim of this paper is twofold; 1) to review the evidence-based proactive steps and actions to greatly reduce the risk of development of an infection or a compromised immune system in sportsmen; and 2) to recommend the course of action for clinicians when they are dealing with an sportsmen and women displaying overt signs of an infection and, or inflammation. Based upon the evidence reviewed-presented herewithin, it can be concluded that it is essential for clinicians to take practical preventative and management steps - actions with sportsmen-women involved in intensive exercise training in order to help preserve a healthy and robust immune system.
\end{abstract}

Keywords: overtraining, immune, cytokines, sports, stress, hormones, sports performance

\section{INTRODUCTION}

The focus of an exercise training program in sportsmen and sportswomen is to improve their physical performance capacity in select sporting events. In attempting to enhance physical performance and cause positive physiological 
adaptations, competitive sportsmen and sportswomen (i.e. athletes) must perform a remarkable amount of exercise on a systematic basis. If the exercise training regimen stresses are excessive (involving working at too great an intensity, and/or containing too great a volume of work), or an athlete has too many additional life stresses (e.g. emotional worry, financial concerns) during training, it is possible for physiological mal-adaptations to occur. Such physiological mal-adaptations can lead to physical performance declines. In the field of exercise physiology this process of applying excessive training stress is referred to as overreaching-overtraining $[3,8,9]$. If overreaching-overtraining is persistently applied to an athlete, then there is the potential for the medical condition called the Overtraining Syndrome to develop in the individual [6, $12,18]$.

The Overtraining Syndrome (OTS) is a physically debilitating medical condition that results in an athlete being totally compromised in their capacity to perform and compete in sporting events. Table 1 presents some of the most common signs and symptoms associated with overtraining and the development of the OTS. The information in Table 1 indicates that a multitude of physiological systems can be affected by the OTS. Recent research evidence points to one system in particular being profoundly affected by overtraining; that system is the immune system. Findings point to a compromise of the immune system when exercise training becomes excessive, and as well documented a compromised immunological function can impact greatly on many aspects of an athlete's health. To this end, the intent of this paper is to provide recommended steps for sports medicine clinicians toward management and care to prevent and, or treat some of the health consequences of overreachingovertraining and OTS as related to the immune system established by using current evidence-based research findings.

\section{Background - immunosuppression}

The actions of the immune system can be divided into what are referred to as the Innate and Adaptive immune responses. The innate responses are the first line of immunological defense and are viewed as indiscriminately attacking pathogens, while the adaptive responses (which typically follow those of the innate) tend to target specific pathogens and have an antigen-specific memory of such pathogens [23]. Figure 1 gives a schematic overview of the general aspects of these components to the immune system. Both the innate and adaptive immune responses are associated with the production of cytokines (see references 1 and 23 for an overview of cytokine type and function). There are a multitude of cytokines that can be produced, and they are typically classified 
as either pro-inflammatory or anti-inflammatory in function; although, some cytokines have both pro- and anti-inflammatory actions [23]. Research by Smith indicates intensive exercise training resulting in skeletal muscle tissue trauma [23]. This tissue trauma from exercise (if excessive) results in the production of an abundance of pro-inflammatory cytokines, which then leads to the development of a sickness response or a chronic fatigue-like behavior in an athlete $[19,20,21]$. The key pro-inflammatory cytokines most associated with this trauma events are; interleukin-1 beta (IL-1 $\beta$ ), interleukin-6 (IL-6) and tumor necrosis factor-alpha (TNF- $\alpha$ ) [1]. Research by several investigators has produced findings that substantiate the role of pro-inflammatory cytokines, especially IL-6, as being key physiological mediator and modulator for development of many of the symptoms associated with OTS (see Table 1) $[20,21]$.

Research evidence points to the production of pro-inflammatory cytokines facilitating the up-regulation of humoral immunity and the suppression of the cell-mediated immunity components of the adaptive immune responses [1, 23]. Because of its immune system role, development of cell-mediated immunosuppression increases the risk of illness or illness-like symptoms such as upper respiratory symptoms (URS) and infections (URI). The development of such an illness or illness-like symptoms can be further associated with compromises in physical performance capacity in athletes - that is, they find exercise training or competition difficult or impossible under such conditions $[5,16$, 25].

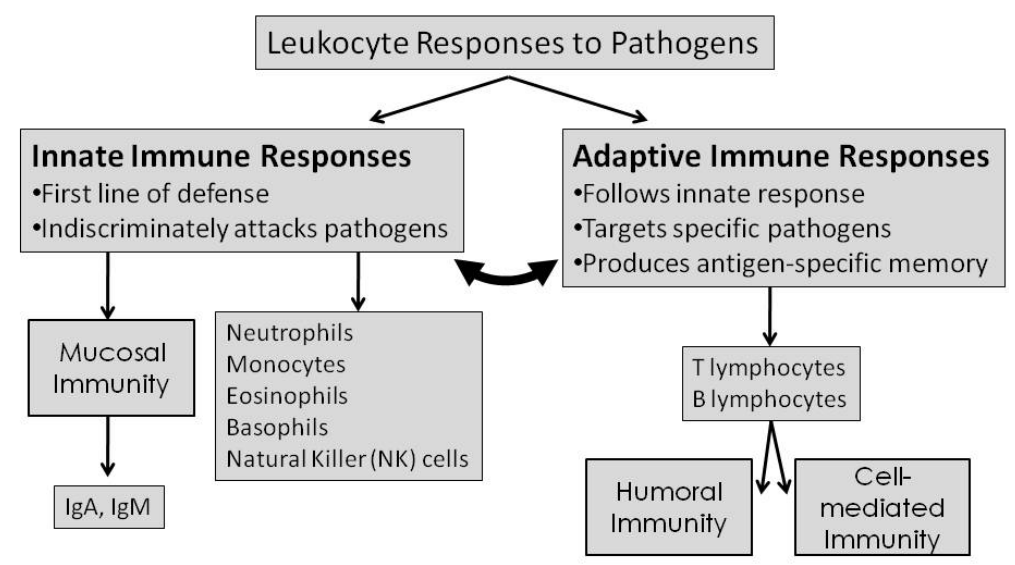

Other components: e.g. acute phase proteins, cytokines, epithelial barriers

Figure 1. Schematic overview of the basic components of the immune system. $\lg A=$ Immunoglobulin $A$; IgM=immunoglobulin $M$ ) 
Table 1. Some of the major signs and symptoms of overtraining and the Overtraining Syndrome

\begin{tabular}{l}
\hline Physiological Function: \\
\hline Decreased competitive performance \\
Decreased muscular strength \\
Increased muscular soreness \\
Chronic fatigue \\
Reduced tolerance to training overload \\
Sleep-wake cycle abnormalities \\
Gastrointestinal disturbances \\
Reduced testosterone levels \\
Reduced thyroid hormone levels \\
Elevated cortisol levels \\
Elevated creatine kinase \\
Altered lactate responses to exercise \\
Reduced sexual drive and libido \\
Altered heart rate responses to exercise \\
Suppressed immunological function \\
\hline Increased feelings of depression \\
Lethargy and apathy \\
Emotional abnormalities \\
Loss of appetite \\
Lack of competitive drive \\
Restlessness \\
Difficulty in concentrating
\end{tabular}

Note: See reference 15 for details

These phenomena of cell-mediated immunosuppression and increased URS-URI risk are in-line with what are referred to as the "Open Window" and "J-Curve Response" concepts which are related to exercise training and illness developmental state as proposed by several eminent health researchers $[13,16,26]$. The open window concept entails that after an intensive exercise session there is a period of time (typically 3-72 hours) in which there is an increased susceptibility to illnesses, such as URI. If there is insufficient daily rest then there can be a cumulative effect of consecutive days of intensive training (i.e. the "window" staying open for a longer period of time). This notion of a period of increased susceptibility to illness following exercise has been linked to the occurrence of natural killer (NK) cell inhibition (part of the innate immune responses [immune-suppression]) that can happen after an exercise session brought on by the increased levels of cortisol, catecholamines, pro-inflammatory cytokines, and increased prostaglandins (from monocytes) in response to the exercise session $[1,7,11,17,26]$. The NK cell suppression in 
turn seems to assist in the aspects of the greater adaptive immune responses and the up-regulation of humoral immunity and down-regulation of cell-mediated immunity $[1,19,23]$. Interestingly, NK cell suppression is especially associated with and found following prolonged-duration endurance (aerobic) forms of exercise activities (e.g. marathon training) which have some of the highest incidences of OTS development $[18,21,24]$. In a similar fashion, the J-curve response concept states that the risk of URI development initially goes down as a sedentary individual gets involved with light to moderate exercise training for health and fitness, but the prevalence substantially increases as the individual advances their training to higher levels of volume and/or intensity such as occurs in individuals wanting to compete in sporting activities; Figures 2 and 3 display diagrammatic depictions of these concepts.

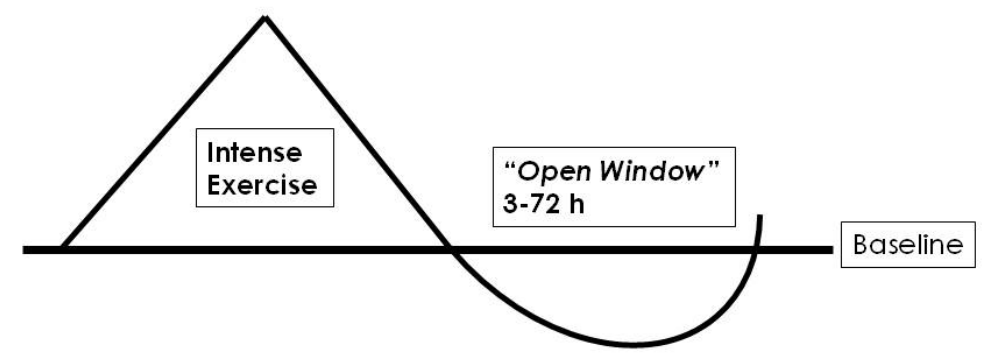

Figure 2. Open Window theoretical concept associated with immune responses to acute exercise. $\mathrm{h}=$ hours

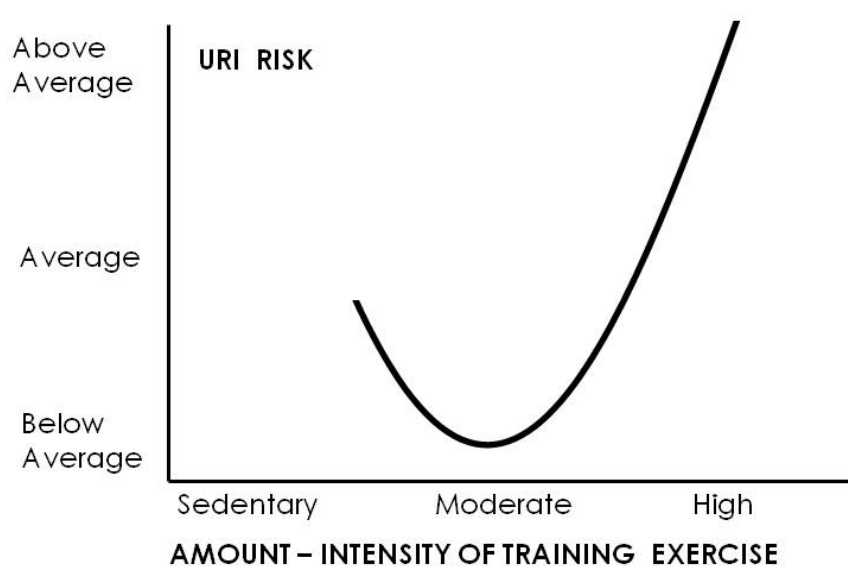

Figure 3. J-Curve response concept associated with the immune responses to exercise training. URI=upper respiratory infections 


\section{Practical aspects of dealing with immunosuppression}

As noted above, the evidence supports that development of exercise training induced immunosuppression is associated with compromised physical performance $[25,26]$. Nevertheless, development of an infection of any type, for any reason, in an athlete can lead to an inability to exercise train or compete at an optimal level $[16,25]$ Therefore, it is important for sports medicine clinicians to take and recognize preventative - treatment steps and actions to allow for maintenance of appropriate immune function and health in sportsmen-women [14].

\section{Prevention}

As with nearly all medical and health conditions, prevention is far superior to treatment in providing for a more successful overall maintenance of the athlete's training regimen and physical performance capacity. Research findings support that there are several proactive steps and actions that sportsmen and sports medicine clinicians can take to greatly reduce the risk of development of an infection or a compromised immune system [22, 25]. These steps - actions include such items as the athlete should;

- Keep vaccine(s) administration updated

- Attempt to minimize contact with known infected or sick people

- Wash hands frequently throughout the day

- Limit mouth/nose contact when with infection symptoms (i.e. URS)

- Do not share drinks with other sportsmen

- Do not share towels or washcloths with other sportsmen

- Isolate team members from others if displaying infection symptoms

- Protect airway from very cold or dry air with performing strenuous exercise

- Maintain adequate daily dietary carbohydrate intake ( $60 \%$ daily caloric intake)

- Wear proper clothing for weather conditions and avoid getting cold-wet after exercise

- Attempt to get a minimum of 7 hours sleep a night

- Avoid rapid weight loss and "crash" dieting approaches to weight loss

- Wear clothing to prevent unnecessary hazardous dermatological exposures (e.g. shower shoes)

- Whenever possible minimize other life stressors

Evidence-based findings support that following these steps can significantly decrease the risk of infections developing in athletes [23, 25]. Obviously, though it may not be completely realistic to incorporate all of the above into the daily behaviors and life-styles of every athlete. 


\section{Treatment}

Even with compliance to all of the abovementioned preventative steps and actions there is always a strong likelihood that an athlete will develop an infection of some type. This occurrence would be apparent if they display such symptoms as; sore throat, coughing, runny/congested nose, muscle/joint pain - edema, headache, fever, malaise, diarrhea and vomiting $[23,25,26]$. Recently, a collection of leading exercise immunologists recommended the following course of action when sports medicine clinicians are dealing with an athlete displaying overt signs of an infection and, or inflammation $[22,25]$.

- Day 1 of Illness - No strenuous exercise or competition; they should drink plenty fluids; keep from getting wet/cold; minimize life-stress. If feverish - induce nasal drainage, and use decongestants-analgesics.

- Day 2 of Illness - If symptoms worsen - no exercise, rest. If no fever or worsening of symptoms; then light-easy exercise (30-45 min) allowed.

- Day 3 of Illness - If fever, symptoms persist consult physician. If no fever or worsening of symptoms; then light-moderate exercise (45-60 $\mathrm{min})$ allowed.

- Day 4 of Illness - If no symptom relief, no exercise - continued rest; have an office visit with a physician. If relief ( $1^{\text {st }}$ day of improved symptoms), and no fever, then light-easy exercise (as noted above). Use the same number days as off to return and step up to normal training; monitor tolerance to gradually increasing exercise intensity, take additional days off if poor tolerance (if necessary).

Finally, in order to optimize treatment, it is critical that all members of the health-care team treating the athlete have good communication with one another concerning the progression and responses of the athlete if symptoms develop and persist $[2,4,10]$.

\section{CONCLUSIONS}

In conclusion, competitive sportsmen (and sportswomen) subject themselves to a high level of exercise training stress in order to enhance their physical performance capacity. This training stress, as well as the other stresses of life these sportsmen encounter, places them at a great risk for developing the OTS. The "cytokine tissue-trauma" hypothesis of OTS proposes that undue proinflammatory cytokine responses to excessive exercise training (overreachingovertraining) creates a "sickness behavior" response, development of immunosuppression, and ultimately leads to a decline in physical performance capacity of the athlete. 
It is critical that sports medicine clinicians take steps to prevent and reduce the risk of infection by helping sportsmen-women to foster and develop appropriate behaviors and actions as recommended above. Likewise, once an infection - inflammation response is manifested in the athlete it is critical for these same clinicians to take the actions to mitigate the severity and impact of the illness development through the recommended intervention steps. By doing so, the clinician can promote a more rapid return to normal health and exercise training level in the athlete.

\section{REFERENCES}

1. Abbas AK, Lichtman AH. (2005) Cellular and Molecular Immunology. Philadelphia, PA: Elsevier Saunders, 88-112

2. Bergeron MF, Nindl BC, Deuster PA, Baumgartner N, Kane SF, Kraemer WJ, Sexauer LR, Thompson WR, O'Connor FG. (2011) Consortium for Health and Military Performance and American College of Sports Medicine consensus paper on extreme conditioning programs in military personnel. Curr Sports Med Rep, 10: 383-389

3. Budgett R, Newsholme E, Lehmann M, Sharp C, Jones D, Peto T, Collins D, Nerurkar R, White P. (2000) Redefining the overtraining syndrome as the unexplained underperformance syndrome. Br J Sports Med, 34: 67-68

4. Christakou A, Lavallee D. (2009) Rehabilitation from sports injuries: from theory to practice. Perspect Public Health, 129: 120-126

5. Czepluch FS, Barrès R, Caidahl K, Olieslagers S, Krook A, Rickenlund A, Zierath JR, Waltenberger J. (2011) Strenuous physical exercise adversely affects monocyte chemotaxis. Thromb Haemost, 105: 122-130

6. Fry AC, Steinacker JM, Meeusen R. (2005) Endocrinology of overtraining. In: Kraemer WJ, Rogol AD. (eds). The endocrine system in sports and exercise. Oxford, UK: Blackwell Publishing, 584-593

7. Gleeson M, Bishop NC. (2005) The T cell and NK cell immune response to exercise. Ann Transplant, 10: 43-48

8. Hackney AC, Battaglini CL. (2007) The Overtraining Syndrome: Neuroendocrine imbalances in sportsmen. Braz J Biomotricity, 1: 34-44

9. Hopkins WG. (2004) How to interpret changes in an athletic performance test. Sportscience, 8: 1-7

10. Jaworski CA, Donohue B, Kluetz J. (2011) Infectious disease. Clin Sports Med, 30: $575-590$

11. Koch A. (2010) Immune response to resistance exercise. Am J Lifestyle Med, 4: 244-252

12. Lehmann M, Lormes W, Opitz-Gress A, Steinacker J, Netzer N, Foster C, Gastmann U. (1997) Training and overtraining: an overview and experimental results in endurance sports. J Sports Med Phys Fitness, 37: 7-17 
13. MacKinnon L. (2000) Overtraining effects on immunity and performance in sportsmen. Immunol Cell Biol, 78: 502-509

14. Mayer F, Bonaventura K, Cassel M, Mueller S, Weber J, Scharhag-Rosenberger F, Carlsohn A, Baur H, Scharhag J. (2012) Medical results of pre-participation examination in adolescent sportsmen. Br J Sports Med, 46: 524-530

15. Meeusen R, Duclos M, Gleeson M, Rietjens G, Steinacker J, Urhausen A. (2006) Prevention, diagnosis and treatment of the Overtraining Syndrome: ECSS Position Statement 'Task Force'. Eur J Sport Sci, 6: 1-14

16. Nieman DC. (2000) Exercise effects on systemic immunity. Immunol Cell Biol, 78: 496-501

17. Perdersen BK. (2000) Exercise and cytokines. Immunol Cell Biol, 78: 532-535

18. Raglin J, Barzdukas A. (1999) Overtraining in sportsmen: the challenge of prevention - a consensus statement. Health Fitness J, 3: 27-31

19. Robson PJ. (2003) Elucidating the unexplained underperformance syndrome in endurance sportsmen. Sports Med, 33: 771-781

20. Robson-Ansley PJ, Demilander L, Collins M, Noakes TD. (2004) Acute interleukin-6 administration impairs athletic performance in healthy, trained male runners. Can J Appl Physiol, 29: 411-418

21. Robson-Ansley PJ, Blannin A, Gleeson M. (2007) Elevated plasma interleukin-6 levels in trained male tri-sportsmen following an acute period of intensive interval training. Eur J Appl Physiol, 99: 353-360

22. Ronsen O. (2005) Prevention and management of respiratory tract infections in sportsmen. New Student Athlete, 20: 49-56

23. Smith LL. (2004) Tissue trauma: the underlying cause of the overtraining syndrome? J Strength Cond Res, 18: 185-193

24. Urhausen A, Gabriel H, Kindermann W. (1995) Blood hormones as markers of training stress and overtraining. Sports Med, 20: 251-276

25. Walsh NP, Gleeson M, Pyne DB, Nieman DC, Dhabhar FS, Shephard RJ, Oliver SJ, Bermon S, Kajeniene A. (2011) Position statement: Part two: Maintaining immune health. Exerc Immunol Rev, 17: 64-103

26. Walsh NP, Gleeson M, Shephard RJ, Gleeson M, Woods JA, Bishop NC, Fleshner M, Green C, Pedersen BK, Hoffman-Goetz L, Rogers CJ, Northoff H, Abbasi A, Simon P. (2011) Position statement: Part one: Immune function and exercise. Exerc Immunol Rev, 17: 6-63

\section{Correspondence to:}

Anthony C. Hackney

University of North Carolina

CB \# 8700 - Fetzer Hall

Chapel Hill, North Carolina

USA

E-mail: ach@email.unc.edu

Tel: 919-962-0334

Fax: 919-962-0489 